\title{
Gender interest differences with multimedia learning interfaces
}

\author{
David Passic
}

Dept. of Educational Technology, School of Education, Bar-Ilan University Israel, Ramat-Can 52900, Israel, email:

passig@ashur.cc.biu.ac.il

\author{
HAYA LEVIN \\ Centre of Informatics, Beit-Berel College, Israel, email: \\ hayale@beitberl.ac.il
}

\begin{abstract}
In this study we examined whether there are gender differences in leaming interest from different designs of multimedia interfaces. In the study we assumed that design characteristics add to the interest in leaming and we developed taxonomy of design of efficient user interfaces both for boys and girls. The research included ninety children from three kindergarten classes, who were exposed to interactive multimedia stories. The research subjects, with the help of a Polymeter (Lampert 1981), answered to questionnaires, which examined their previous experience with a computer, their level of time on task and their level of satisfaction with the various interfaces. The research findings indicate that there is a significant difference between boys and girls in the influence of the design of the leaming interfaces on their level of time on task as well as on their level of satisfaction with the different interfaces. Boys on the one hand had a higher level of time on task, and were more familiar with computer games and looked for assistance through navigational buttons. Girls on the other hand tended to ask for help with the game. Girls preferred to include writing into the game and preferred colorful screens full of drawings, which changed stowly. We also found that boys preferred green and blue colors, whilst the gints preferred red and yellow. Cenerally speaking, we found that girls preferred the components of the Mise-en-scene interface, and boys preferred the components of the Montage interface.
\end{abstract}

\section{Introduction}

The aim of the research was to examine kindergartners gender differences in using multimedia learning interfaces, and try to isolate multimedia interface characteristics that interested girls more than boys and vice versa. This is in order to make multimedia learning more efficient for both genders. 
Multimedia Learning User-Interface is what connects the computer with the user; it is the means of interaction between the two (Lucas 1991). The user does not only learn the content, but $s /$ he also learns how to deal with the synthetic programmed environment. The ease of use, and the uniformity of the interface, has great implications, since they may make possible a higher level of concentration on the material being studied (Edward \& Holland 1992). The design of the interface must provide a representation of clear, consistent and attractive communications, since the quality of the interface contributes towards the ability of the user to reach excellence (Lucas 1991).

A distinction must be made between an internal multimedia interface-Interface, and an external multimedia interface-Outface. The Interface is a multi-sensory means of hardware and software, which connects the user to the computer. In contrast, the Outface is the computer screen-the display landscape. The style of display has a great influence on the learning process (Levin 1997).

Weiss (1994) sees multimedia interface as though it is made up of a number of separate units:

a. The display interface-controls the way in which the user sees the information.

b. The conversation interface-which controls the manner of the system's communications with the user and the user with the system.

c. The navigation interface controls the way in which the user moves from one part to another part.

d. The mouse interface-controls the way in which the user controls the different activities, by means of icons and windows.

Accordingly, the visual design of the interface affects the impression that the user has of the interface, the understanding of the interface and the desire to use it (Mayes 1992). This research is based upon the assumption of the psychological approach design theory which claims that a friendly interface, using clear signs, must be designed, in order to extract the educational potential of computers in education (Crook 1991).

In order to simplify the elements of the interface we used two concepts from the world of cinema:

a. Mise-en-scene, which deals with pagination of single scenes.

b. Montage, which deals with the combination of scenes and the transition from one scene to the next (Hodges \& Sasnett 1993).

In this research we examined how the different components of the interface created a positive emotional reaction to the media, or in other words, intrinsic satisfaction (Holland, Solomon and Afreeza 1987).

We examined the components of the interface in relation to the different computer utilization by genders. Until recently common believe was that males intelligence superior to females intelligence. Following the introduction of the intelligence tests into the education system, the question of the difference in intelligence between genders raised an appeal interest.

The source of the unequal attitude based on sexual stereotypes. It is derived from the assumption, and from the belief that sexual identity clearly determines the functioning, ability, desires, qualifications and other signs of behavior of each of the members of the two sexes. 
In this research we attempted to detect the most suitable interface for boys and girls, in order to prepare computerized experiences without any difference between the sexes. We did indeed find clear differences between boys and girls, in the influence of the learning interface design, on the level of interest and satisfaction of the various interfaces. Some of the findings supported other findings that are in the literature and some are being reported here for the first time. In general, we found that girls preferred the components of the Mise-en-scene interface and boys preferred the components of the Montage interface.

\section{The method}

Ninety children took part in this study, 44 girls and 46 boys, from three kindergarten classes, in two age groups: 4-5 years old, 5-6 years old. The interest in multimedia interfaces was measured by the criteria of intrinsic satisfaction-positive emotional reaction connected to the actual activity.

Every group was exposed to interactive multimedia stories for improving reading skills. These educational computer programs enabled the child to be active in the reading process, whilst being exposed to different communication modules: visual, aural and movement (Chu 1995). These electronic stories enabled young children to experience the reading of a story in an unconventional way, where the reader only has to click on the mouse in order to communicate with the book.

The experiment shows that young children have great interest in reading computer stories, as they find computer books enjoyable, and they enable the child to be active in her/his own way. A child can click at pace suitable to him/her and in the place that interests her/him, whilst responding in a spontaneous and kinetic manner during the reading. Each child can read the story alone, and can act in his/her own way thus the reading experience becomes personal, easy, enjoyable and more interesting (Chu 1995).

The three educational computer programs that were chosen, each one from a different publisher, are designed differently from the aspects of the dominant colors, the quality of the animation and the quality of the sound, the variety of possibilities spread before the child, and in the level of interactivity of the learning program.

Each subject being examined tried one learning program, prior to which s/he was asked to answer a questionnaire which examined the subject approach to activities in kindergarten (Frenkel 1988), and her/his previous computer experience. Immediately after the activity s/he was asked to answer a $2^{\text {nd }}$ questionnaire which examined the level of the intrinsic satisfaction from the various interfaces (Weiss 1994).

The user satisfaction questionnaire, which was circulated after the experiment, examined subjects' satisfaction with the design of the interfaces. The questionnaire related to user satisfaction concerning four aspects: display interface (seeing the information), conversation interface (communications between user and system), navigation interface (movement from place to place) and mouse interface (use of icons). In total, there were 41 statements in the questionnaire developed by Shneiderman (1992), and adapted to this research population (Tables no. $1-4$ ). 
Tables No. 1-4: The series of stafements about the interfaces

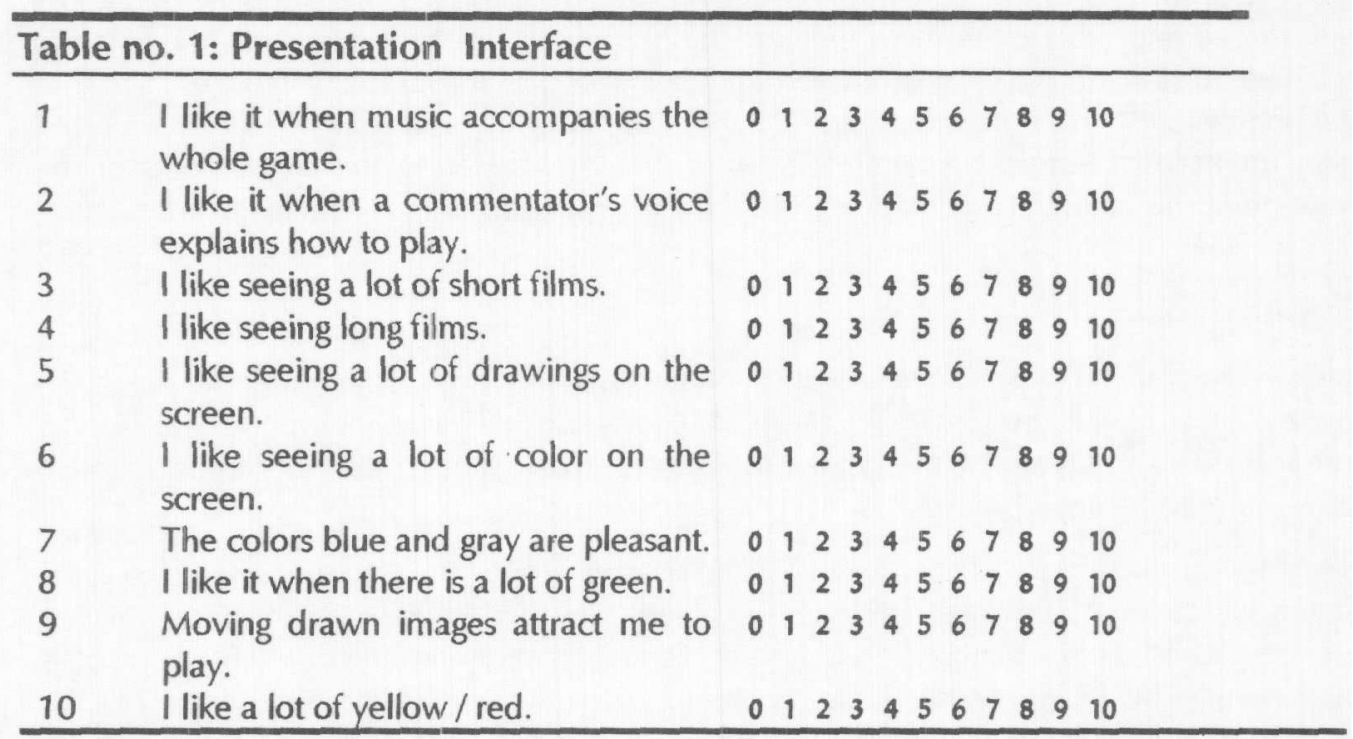

\section{Table no. 2: Conversation Interface}

1 I like hearing the voice talking, when I 012123445678910 want to...

2 It is good that I can change my mind $0 \begin{array}{lllllllll}2 & 34 & 5 & 6 & 7 & 8 & 9\end{array}$ and make another move as I wish.

3 I like it that when I make a mistake the $\begin{array}{llllllllll}0 & 1 & 2 & 3 & 4 & 5 & 6 & 7 & 8 & 9\end{array}$ computer helps me understand.

$4 \quad$ I like it when there is a large choice. $\quad 0 \quad 123345678910$

5 I like it when I am told to write things $\begin{array}{llllllllll}0 & 1 & 2 & 3 & 4 & 5 & 6 & 7 & 8 & 9\end{array}$ during a game. 


\section{Table no. 3: Navigation Interface}

$1 \quad$ I have to know how to carry on with the $\begin{array}{lllllllll}0 & 1 & 2 & 3 & 4 & 5 & 6 & 7 & 9\end{array}$ game.

$2 \quad I$ need it to be easy for me to go 0122345678910 backwards in a game.

3 I have to see the navigational buttons all $0 \begin{array}{lllllllll}2 & 3 & 4 & 5 & 6 & 8 & 9 & 10\end{array}$ the time.

$4 \quad$ I like surprises after every click.

$0 \begin{array}{llllllllll}0 & 1 & 3 & 4 & 5 & 6 & 7 & 8 & 9 & 10\end{array}$

I like quick transitions.

$\begin{array}{lllllllllll}0 & 1 & 2 & 3 & 4 & 5 & 6 & 7 & 8 & 9 & 10\end{array}$

I like a slow pace for a game.

$\begin{array}{lllllllllll}0 & 1 & 2 & 3 & 4 & 5 & 6 & 7 & 8 & 9 & 10\end{array}$

I like it when the whole screen changes at $\begin{array}{llllllllllll}0 & 1 & 2 & 3 & 4 & 5 & 6 & 7 & 8 & 9 & 10\end{array}$ once.

$8 \quad$ I like it when only parts of the screen 0122345678910 change.

$9 \quad$ I am surprised every time animation $\begin{array}{llllllllllll} & 1 & 2 & 3 & 4 & 5 & 6 & 7 & 8 & 9 & 10\end{array}$ appears.

10 I like it when there is animation at the $\begin{array}{llllllll}1 & 23456789 & 0\end{array}$ whole of the screen.

11 I like it when there is animation at the top $\begin{array}{lllllllllll}0 & 1 & 2 & 3 & 4 & 5 & 6 & 7 & 8 & 9 & 10\end{array}$ of the screen.

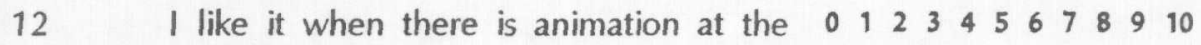
bottom of the screen. 


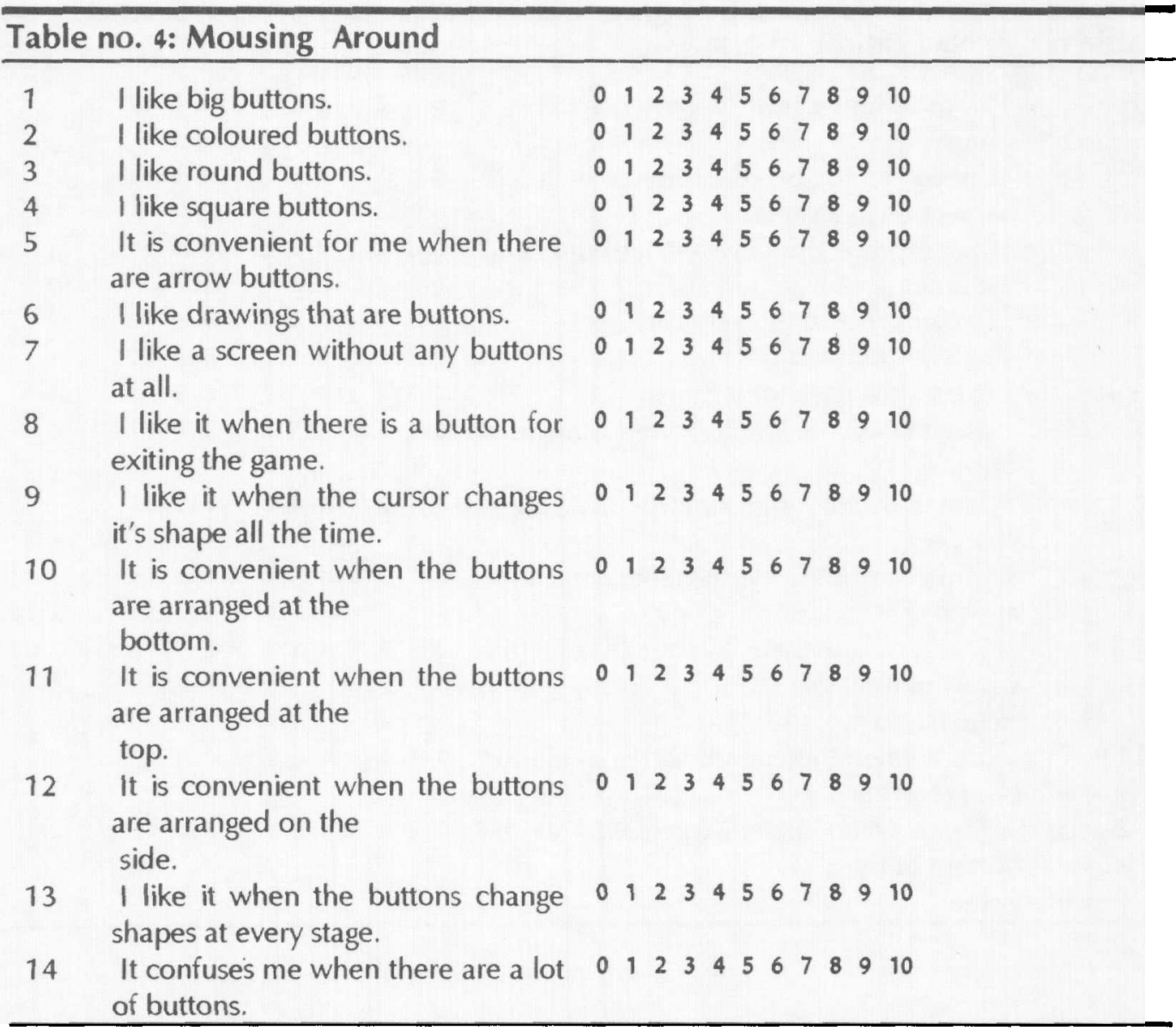

Due to the young age of the research subjects we used the Polymeter Ruler (Lampert 1981), with a scale of two colors, black and white, in order to provide them with a simpler method how to express their opinion concerning the series of statements in the questionnaire.

Lampert's Polymeter is an instrument for measuring behavior, based on visual moving elements, that enable almost anyone to present their opinion, on a continuous scale, without difficulty. The Polymeter comprises of two basic units: a housing unit having a rectangular opening, and a colored ruler that moves in the housing. The research subject moves the ruler in order to indicate his opinion towards any subject by dividing the area seen in the window between two colors, where the one represents the negative and the other the positive.

The Polymeter has many advantages, mainly with young subjects. Its simple structure makes it possible for everyone to express his or her opinion without difficulty. It does not depend on the verbal ability of the user and it enables the subject to expose himself to other visual alternatives, before making a decision (Lampert 1978). 


\section{Results}

We carried out a $\mathbf{T}$ test in order to examine the assumption that there will be found differences between boys and girls concerning time on task and intrinsic satisfaction of multimedia interfaces, (table no. 5). Table no. 5 points out to significant gender differences regarding prior experience, intrinsic satisfaction to multimedia learning interface, and regarding time on task.

Table no. 5: Averages S.D and T values of gender differences regarding prior experience, intrinsic satisfaction of interactive story, and time on task

\begin{tabular}{|c|c|c|c|c|c|}
\hline Sex & Girls & $N=44$ & Boys & $N=46$ & \\
\hline Statements & S.D & Average & S.D & Average & $T$ \\
\hline $\begin{array}{l}\text { Prior } \\
\text { experience } 1\end{array}$ & (4.25) & 3.22 & (4.27) & 5.73 & $2.79 * *$ \\
\hline $\begin{array}{l}\text { Prior } \\
\text { experience } 4\end{array}$ & 1.59 & 9.00 & $(0.60)$ & 9.81 & 1.99* \\
\hline $\begin{array}{l}\text { Satisfaction of } \\
\text { story } 2\end{array}$ & $(2.52)$ & 7.71 & $(2.00)$ & 9.50 & $2.16^{\circ}$ \\
\hline $\begin{array}{l}\text { Satisfaction of } \\
\text { story } 4\end{array}$ & (2.72) & 8.11 & (1.57) & 9.13 & $2.15 *$ \\
\hline $\begin{array}{l}\text { Satisfaction of } \\
\text { story } 5\end{array}$ & $(4.18)$ & 6.27 & $(3.38)$ & 8.10 & $2.29 "$ \\
\hline Time on task & (1.35) & 9.21 & $(0.30)$ & 9.90 & $2.15^{*}$ \\
\hline
\end{tabular}

$* \mathrm{P}<0.05 * * \mathrm{P}<0.01$

From looking at table no. 5 it seems that a significant difference was found between boys and girls average regarding prior experience with computers. It seems that boys more than girls use to play computers at home (5.73 opposite 3.22 ). In addition, in group no. 1 a significant difference between boys and girls average was found regarding prior experience with computers, while boys more than girls admitted they can play by themselves with a computer (9.81 against 9.00 ).

A significant difference was found among boys and girls average in the following subjects regarding intrinsic satisfaction of interactive stories:

Boys show higher satisfaction than girls (9.50 opposite 7.71$)$ do in playing multimedia games (in-group no. 2).

Boys more than girls understand how to continue with the game based on the outface (9.13 opposite 8.11 ).

Boys more than girls ( 8.10 opposite 6.27 ) claim that a large amounts of choices in the game interface help them play. 
A significant difference was found among boys and girls average regarding to Time on task (in-group no.1). Boys (9.90 opposite 9.21 ) pay attention to the work with computers more than girls.

However there is no significant difference between boys and girls concerning cover time on task.

The following table, (no. 6), describes significant findings regarding gender differences in intrinsic satisfaction of learning multimedia interfaces.

Table no. 6: Averages, S.D. and T values to exam gender differences regarding intrinsic satisfaction of learning interfaces

\begin{tabular}{lccccc}
\hline Sex & Girls & N=44 & Boys & N=46 & \\
\hline Interface & S.D & Average & S.D & Average & T \\
Conversation 5 & $(3.57)$ & 7.36 & $(4.45)$ & 5.84 & $-\mathbf{1 . 7 7 *}$ \\
Presentation 3 & $(4.05)$ & 5.84 & $(3.98)$ & 4.04 & $\mathbf{- 2 . 1 2 ^ { * }}$ \\
Presentation 4 & $(4.50)$ & 4.00 & $(3.50)$ & 1.84 & $\mathbf{- 2 . 5 1 ^ { * }}$ \\
Presentation 5 & $(2.68)$ & 8.97 & $(3.19)$ & 7.80 & $\mathbf{- 1 . 8 8 ^ { * }}$ \\
Presentation 8 & $(4.01)$ & 5.38 & $(3.78)$ & 6.86 & $\mathbf{1 . 8 0 *}$ \\
Navigation 7 & $(4.15)$ & 5.02 & $(4.02)$ & 7.46 & $\mathbf{2 . 8 2 * * *}$ \\
Navigation 8 & $(4.08)$ & 2.97 & $(4.21)$ & 6.08 & $\mathbf{3 . 5 5 * * *}$ \\
\hline
\end{tabular}

Table no. 6 points out to a significant difference between boys and girls regarding intrinsic satisfaction of interfaces in the following subjects:

Girls prefer (7.36 opposite 5.84) writing during the game (conversation 5).

Girls more than boys (5.84 opposite 4.04 ) prefer many short movies (presentation 3).

Girls more than boys (4.00 opposite 1.84) don't like watching long movies (presentation 4).

Girls more than boys ( 8.97 opposite 7.80 ) like seeing many paintings on the outface (presentation 5).

In-group no. 3 the findings emphasize the fact that girls more than boys $(9.81$ opposite 7.10) like colorful screens. On the other hand, the findings indicate those boys more than girls (6.86 opposite 5.38) prefer green color (presentation 8).

Regarding the navigation interface, it seems that boys more than girls (7.46 opposite 5.02 ) like the screen changing at once (navigation 7). Regarding the mouse interface, findings indicate that boys (6.08 opposite 2.97 ) don't like it when only part of the screen changes (navigation 8). 
Generally, there was no agreement among the three groups. In each group there were different satisfactions. In-group no. 1 girls more than boys (6.57 opposite 3.09 ) preferred big buttons; boys in group no.1 more than the girls (8.63 opposite 5.42) preferred to see arrow buttons; and buttons that change their form (7.06 opposite 4.00). In-group no. 2, boys more than girls (9.18 opposite 5.71 ) preferred having an exit button.

Finally, the significant findings indicate the existence of a different attitude between boys and girls toward different issues:

Boys seem to have more experience than girls do in PC games.

Boys also show interest during the game, while girls have more interest in the visual side of the game.

\section{Discussion}

We have assumed that differences would be found among boys and girls in learning interest with multimedia interfaces. The findings indicated, that boys and girls differ in Time on task and in intrinsic satisfaction with multimedia learning interfaces, while girls emphasize writing, colors, drawings, help and a calm game, boys on the other hand, emphasize control over the computer, sharp moves and many movement on the screen. These findings sharpen the effect of the learning program and the specific interface, whilst the manner of presenting the information and the ease of dialogue between the user and the system affect the user's desire to use it.

In this research, concerning the interest of learning with multimedia interfaces, an initial attempt was made to throw light on the objects of interest of the kindergartners (boys and girls), in order to enable the education system to focus on these objects of interests. The theories of gender differences in education try to analyze how and why differences between the genders are formed. It is natural that the order of importance of things will be different between boys and girls, as a result of their being different biologically and from the point of view of stereotype behavior. In part of the findings, boys and girls looked at an item in the same way and ascribed to a certain item the same level of importance, but there are statements that were given a high rating, which were more common with boys, and statements that were given a high rating, that were more common with girls.

As for Time on task it was found that boys pay more attention than girls to working on the computer while playing (9.90 opposite 9.21). Another one, in which boys more then girls tend to play computers at home (5.73 opposite 3.22$)$ supports this finding.

As for intrinsic satisfaction of multimedia educational software (interactive stories), we found that boys more than girls did, enjoyed playing on the computer, (9.0 opposite 7.71 ) and they better understood how to continue playing (9.13 opposite 8.11).

These findings match other findings (Comber 1997, Kinnear 1995, Durandell 1995, Busch 1995 and Johanson 1985) in which boys, more than girls, were exposed to the world of computers and spent their free time on computer games.

We also found that girls preferred more than boys did to write during the game, as it is expressed in the research of Plamondon (1994). Girls preferred the screen to be colorful and filled with drawings. Girls more than boys preferred the movement on the screen to be slow and the changes to be gradual. These findings match the findings of Jakobsdottir, 
Kors \& Sale (1994), which points out that difference between boys and girls manifest in creativity and in preference of graphic elements. We found that girls, more than boys, were aware of the color issue, while boys more than girls, were aware of movement.

We also found that boys significantly preferred the green color, while studies indicate to the existence of color difference in preference between boys and girls, and that boys preferred the green. It is sate to assume that boys and girls appreciated the colour variable in a different way because of the followings:

The generic element which effect the emotional concept of colors.

The cultural influence and the high sensitivity of girls toward the element of color as apart of the feminine stereotype (Fischer 1988).

The findings which are partially significant, indicate the existence of interest differences among boys and girls, in which girls are more drawn in the field of "Mise en scene", while boys are more drawn in to the field of "Montage" (Hodges \& Susnett 1993).

\section{Summary and recommendations}

The study carried out by Colly, Hill \& Jones (1995) on the differences between the genders in the use of computers, indicates that girls, compared to boys, are in an inferior position concerning their image as to their control of technologies and do not reach their full potential. In this way human capital, which is hidden in a half of the learning population, is wasted. Therefore, the use of the multimedia interface can solve some of these problems, since the visual design of the multimedia interface, the manner of presenting the information and the ease of dialogue between the user and the system, affect the user, both from the aspect of understanding the material and from the aspect of the desire to use it. The algorithms that define the manner of presenting the screen and the form of the screen, define, not only the efficiency of the interface, but also the personal preferences of the computer user. The contents of the screen, and the management of the screened message, are important in the diagnosis of the information and the processing of this information presented by means of it.

In this research, an initial attempt was made to examine the differences of satisfaction with multimedia learning interfaces between boys and girls. Based on this initial examination, it is recommended to try to develop a model of styles of design for learning interfaces in multimedia, for boys and girls. It can be assumed that the development of a model like this will be important for the development of multimedia computer learning programs for the education system, that suit the different learning interests of both genders. However, since no empirical studies were found in this specific area, this research recommends carrying out additional researches whose ain is to establish, substantiate and extend the findings of the current research, and create gender equality in educational practice (Severiens \& Dam 1997). 


\section{References}

Busch, T. (1995) Gender differences in self-efficacy and attitudes toward computers. J. Educational Computing Research, 12(2), 147-158.

Chu, M. (1995) Reader response to interactive computer books: examining literary responses in a non-traditional reading setting. Reading Research and Instruction. 34, 352-366.

Comber, C., Colley, A. Hargreaves, D.J., \& Dorn, L. (1997) The effects of age, gender and computer experience upon computer attitudes. Educational Research, 39 (2), 123-133

Crook, C. (1991) Computers for pre-school children: the role of direct manipulation interfaces. Early Child Development and Care, 69, 5-18.

Durandell, A., Glissov, P., \& Siann, G. (1995) Gender and computing: persisting differences. Educational Research, 37(3), 219-228.

Edwards, A.D.N., \& Holland, S. (1994) Multimedia interface design in education. University of Aberdeen, UK.

Fischer, P. (1988) The relationship between colour preference, age, cognitive development and sex. MA Thesis, School of Education, Bar-Ilan University, Israel.

Hodges, M.E., \& Sasnett, R.M. (1993) Multimedia computing. Reading, MA:

Addison-Wesley Publishing Company, Inc.

Holland, G., Solomon, G., \& Afreeza, D. (1987) The analysis of behavior in instruction. University of Pittsburgh, Learning Research and Development Center, USA

Jakobsdottir, S., Kery, C.L., \& Sales, G.C. (1994) Computer graphics: preferences by gender in grades 2, 4 and 6. Journal of Educational Research, 88(2), 97-99.

Johanson, R.P. (1985) School computing: some factors affecting student performance. American Educational Research ASSO, Annual Meeting, Chicago.

Kinnear, A. (1995) Introduction of microcomputers: a case study of patterns of use and children's perceptions. J. Educational Computing Research, 13(1), 27-40.

Lampert, S. I. (1979) The attitude pollimeter: A new attitude scaling device. Journal of Marketing Research, 16, 578-582.

Lampert, S. I. (1981) A new scale for consumer research: The pollimeter combines properties for data collection and data analysis. Journal of Advertising Research, 21(2), 23-29.

Levin, H. (1997) Gender differences in learning interest among pre-schoolers as derived from multimedia interfaces design. MA Thesis, School of Education, Bar-llan University, Israel.

Lucas, L. (1991) Visually designing the computer-learner interface. Educational Technology' July, 56-58. 
Mayes, J.T. (1992) The "M-Word": multimedia interfaces \& their role in interactive learning systems. In A.D.N. Edwards, \& S. Holland (Eds.), Multimedia Interface Design in Education (pp. 1-22). University of Aberdeen, UK.

Plamondon, K. (1994) Gender differences among early elementary students in computer use and interest. Teaching and Change, 1 (3), 284-294.

Severiens, S. \& Dam, G. T. (1997) Gender and gender identity differences in learning styles. Educational Psychology, 17(1 \& 2), 79-93.

Shneiderman, B. (1992) Designing the user interface, strategies for effective humancomputer interaction. Mass: Addison Wesley.

Snir, N. (1989) The media and the student, the influence of educational technologies (computer, television, student's notebook) on achievement, motivation and time-on-task. . MA Thesis, Bar-llan University, Israel.

Wrigley, J. (1992) Education and gender equality. London: The Palmers Press.

Weiss, E. (1994) Making computer people-literate. San Francisco: Jossy-Bass Publishers. 